\title{
Contributors to linkage between Arctic warming and East Asian winter climate
}

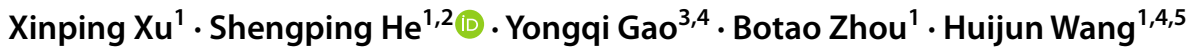

Received: 6 November 2020 / Accepted: 18 May 2021 / Published online: 5 June 2021

(c) The Author(s) 2021

\begin{abstract}
Previous modelling and observational studies have shown discrepancies in the interannual relationship of winter surface air temperature (SAT) between Arctic and East Asia, stimulating the debate about whether Arctic change can influence midlatitude climate. This study uses two sets of coordinated experiments (EXP1 and EXP2) from six different atmospheric general circulation models. Both EXP1 and EXP2 consist of 130 ensemble members, each of which in EXP1 (EXP2) was forced by the same observed daily varying sea ice and daily varying (daily climatological) sea surface temperature (SST) for 1982-2014 but with different atmospheric initial conditions. Large spread exists among ensemble members in simulating the Arctic-East Asian SAT relationship. Only a fraction of ensemble members can reproduce the observed deep Arctic warming-cold continent pattern which extends from surface to upper troposphere, implying the important role of atmospheric internal variability. The mechanisms of deep Arctic warming and shallow Arctic warming are further distinguished. Arctic warming aloft is caused primarily by poleward moisture transport, which in conjunction with the surface warming coupled with sea ice melting constitutes the surface-amplified deep Arctic warming throughout the troposphere. These processes associated with the deep Arctic warming may be related to the forcing of remote SST when there is favorable atmospheric circulation such as Rossby wave train propagating from the North Atlantic into the Arctic.
\end{abstract}

Keywords Arctic-midlatitude linkage $\cdot$ Deep Arctic warming $\cdot$ Shallow Arctic warming $\cdot$ Poleward moisture transport . Coordinated climate model experiments

\section{Introduction}

The rapid Arctic sea ice decline is one of the most striking manifestations of the recent climate change (Fetterer et al. 2017; He et al. 2018; Stroeve et al. 2012). Mostly caused

Shengping $\mathrm{He}$

Shengping.He@uib.no

1 Collaborative Innovation Center on Forecast and Evaluation of Meteorological Disasters/Key Laboratory of Meteorological Disaster, Ministry of Education, Nanjing University of Information Science \& Technology, Nanjing, China

2 Geophysical Institute, University of Bergen and Bjerknes Centre for Climate Research, Bergen, Norway

3 Nansen Environmental and Remote Sensing Center and Bjerknes Centre for Climate Research, Bergen, Norway

4 Nansen-Zhu International Research Center, Institute of Atmospheric Physics, Chinese Academy of Sciences, Beijing, China

5 Climate Change Research Center, Chinese Academy of Sciences, Beijing, China by sea ice loss, the Arctic surface has warmed 2-3 times of the greenhouse gas-induced global warming, a phenomenon known as Arctic amplification (Dai et al. 2019; Screen and Simmonds 2010; Serreze et al. 2009). Local feedbacks associated with Arctic sea ice loss and radiative processes (Cohen et al. 2014; Kumar et al. 2010), and remote forcing including poleward warm and moist air intrusion (Kim et al. 2017; Svendsen et al. 2018) and increased ocean heat advection into the Arctic (Årthun et al. 2012; Docquier et al. 2021; Koenigk and Brodeau 2014; Spielhagen et al. 2011) have been hypothesized to contribute to Arctic surface warming. Even now, the causes of Arctic warming are not fully understood (Screen 2017a). The simulated Arctic warming in climate models differs from the observation, especially at the mid- and upper-troposphere over the Arctic (Cohen et al. 
2020; Meleshko et al. 2016; Screen et al. 2012). Contrary to the consensus that near-surface warming is greatly coupled with sea ice reduction, Arctic warming aloft is argued more associated with remote sea surface temperature (SST) and warm moist air transported from lower latitudes to the Arctic (Graversen et al. 2008; Ogawa et al. 2018; Perlwitz et al. 2015).

Concurrent with Arctic warming, strong cooling trends and frequent cold weather patterns emerge in Eurasia since the late 1990s (Cohen et al. 2014; Johnson et al. 2018; Liu et al. 2012), particularly in East Asia (Gao et al. 2015; Kug et al. 2015; Wang and Chen 2014), forming the so-called "warm Arctic-cold continent" pattern (Overland et al. 2011). As one of the most significant climate systems in the Northern Hemisphere during winter (Chen and Sun 1999; Huang et al. 2003), the East Asian winter monsoon (EAWM) has profound influence on the East Asian winter climate (Tao and Chen 1987). The EAWM has experienced a remarkable interdecadal weakening from the mid-1980s to the early 2000s (He and Wang 2012), followed by a reversal towards a strengthening trend in recent decades (Wang and Chen 2014). Arctic amplification might provide enhanced moisture sources (Liu et al. 2012) and enhance snowfall over Siberia (Cohen et al. 2012), which is closely tied to the intensified EAWM (Zhou 2017). Furthermore, Arctic warming is an important factor of blocking frequency over the Ural Mountains (Mori et al. 2014) and can influence the intensity of the EAWM through eastward propagation of Rossby waves (Cheung et al. 2012; Cohen et al. 2014; Honda et al. 2009; Takaya and Nakamura 2005; Zhou 2017). However, no consensus has been reached; for instance, some climate model simulations fail to reproduce winter cooling (Ogawa et al. 2018; Screen 2017b) and colder conditions (McCusker et al. 2016; Sun et al. 2016) over Eurasia in response to reduction of Arctic sea ice. The divergence between observational and modelling results, and among modelling experiments which test the midlatitude atmospheric circulation response to the specified Arctic sea ice loss, fueled the debate about the teleconnection between Arctic warming and midlatitude climate (Francis 2017; Screen et al. 2018; Vavrus 2018). Moreover, the observed time period is short and extratropical natural variability is extremely large, which makes it difficult to judge how robust more frequent occurrence of cold extremes really was (Koenigk and FuentesFranco 2019; Ogawa et al. 2018). And an increasing number of studies argued the role of atmospheric internal variability on the "warm Arctic-cold continent" pattern (Sorokina et al. 2016; Sung et al. 2018; Xu et al. 2019). Other factors such as SST in the midlatitudes and tropics (Matsumura and Kosaka 2019; Sato et al. 2014) and Eurasian snow cover (Xu et al. 2018) have also been suggested to explain the Arctic-midlatitudes linkage. While it has been recently proposed that climate models might inadequately capture the remote Arctic influence (Francis 2017; Smith et al. 2017). Based on coordinated simulations from seven atmosphere general circulation models (AGCMs), Mori et al. (2019) suggested that about $44 \%$ of the Eurasian cooling trend can be explained by the sea ice loss in the Barents-Kara Seas. However, the forced surface temperature response to the sea ice loss is underestimated.

Previous work has revealed the influence of Arctic warming on the EAWM system and substantiated significant negative correlation between surface air temperature (SAT) anomalies over the Barents-Kara Seas and East Asia using 39 Coupled Model Intercomparison Project phase 5 (CMIP5) models (Kug et al. 2015). In this paper, we assess the ability of individual ensemble members of AGCMs in simulating the linkage between Arctic warming and East Asian colder conditions and focus on the physical factors determining the linkage, using the coordinated multi-model ensemble experiments performed under the GREENICEproject (Ogawa et al. 2018). Multi models for coordinated experiments ensure the robust results across different models with the same boundary conditions (Screen et al. 2018).

\section{Model experiments and methods}

We utilize the output from the existing coordinated experiments described in Ogawa et al. (2018). Daily varying sea ice and daily varying SST from the National Oceanic and Atmospheric Administration (NOAA) (Reynolds et al. 2007) (download from http://www.ncdc.noaa.gov/sst/index.php) during 1982-2014 are prescribed in the first set of experiment (EXP1). Daily varying sea ice and daily climatological SST are prescribed in the second set of experiment (EXP2). The climatological SST at the marginal sea ice zone is treated according to Screen et al. (2013) in order to be consistent with the sea ice variations. The two experiments are performed using five different AGCMs (CAM4, WACCM, IFS, IAP4, and LMDZOR) with different resolutions and parameterizations (Table 1). An ensemble of 20 simulations with different initial conditions is performed for each of the five models. Another 30-member experiment is performed prescribing monthly mean sea ice and SST data from Hurrell et al. (2008) by using the sixth atmospheric model (AFES; Table 1). External forcing of these experiments follows the CMIP5 protocol, that is historical forcing from 1982 to 2005 and RCP8.5 emission scenario from 2006 to 2014.

Monthly SAT and atmospheric variables from European Centre for Medium-Range Weather Forecasts Interim (ERA-I) reanalysis (Dee et al. 2011) are employed. The Arctic and East Asian SAT indices (ARTI_2m and EATI_2m) are defined as area-averaged SAT over the Barents-Kara Seas $\left(30^{\circ}-70^{\circ} \mathrm{E}, 70^{\circ}-80^{\circ} \mathrm{N}\right)$ and East Asia $\left(80^{\circ}-130^{\circ} \mathrm{E}, 35^{\circ}-50^{\circ} \mathrm{N}\right)$, respectively (Kug et al. 2015). 
Table 1 List of the six models

\begin{tabular}{lllll}
\hline Model name (reference) & Horizontal resolution & Vertical layers & Top level (hPa) & $\begin{array}{l}\text { Ensemble } \\
\text { members }\end{array}$ \\
\hline CAM4 (Neale et al. 2013) & $0.9^{\circ} \times 1.25^{\circ}$ & 26 & 3 & 20 \\
WACCM (Marsh et al. 2013) & $0.9^{\circ} \times 1.25^{\circ}$ & 66 & 0.000006 & 20 \\
IFS (Balsamo et al. 2009) & T255 & 91 & 0.01 & 20 \\
IAP4 (Dong et al. 2012) & $1.4^{\circ} \times 1.4^{\circ}$ & 26 & 10 & 20 \\
LMDZOR (Hourdin et al. 2013) & $2.5^{\circ} \times 1.25^{\circ}$ & 39 & 0.04 & 20 \\
AFES (Ohfuchi et al. 2004) & $1.5^{\circ} \times 1.5^{\circ}$ & 56 & 0.09 & 30 \\
\hline
\end{tabular}

The Arctic tropospheric temperature index (ARTI_500) is defined as area-averaged $500 \mathrm{hPa}$ temperature over the Barents-Kara Seas (He et al. 2020). The high (low) ARTI_2m years are defined when the winter ARTI_2m is equal or greater (less) than $0.5(-0.5)$ standard deviation. The winter of 1982 refers to December in 1982 and January and February in 1983.

The Rossby wave source is defined as $-\nabla \cdot V_{x}(f+\xi)$ according to Sardeshmukh and Hoskins (1988). Here, $V_{x}$ is the divergent wind, $f$ is the Coriolis parameter, and $\xi$ is the absolute vorticity.

(a)

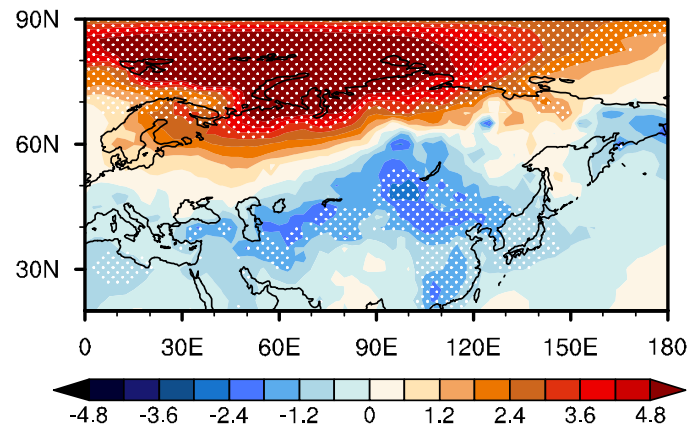

\section{Results}

Figure 1 shows the composite winter climate anomalies (that is, high ARTI_2m minus low ARTI_2m years during 1982-2013) in the reanalysis data. The "warm Arctic-cold continent" anomaly pattern and corresponding atmospheric circulations (quasi-equivalent barotropic anticyclonic flow in northern Eurasia and upper-tropospheric cyclonic flow in East Asia) agree well with prior studies (Kug et al. 2015; Mori et al. 2014). It has been increasingly recognized that there are two-way connections between Arctic change and midlatitude atmospheric circulations (Screen 2017a). Arctic (c)

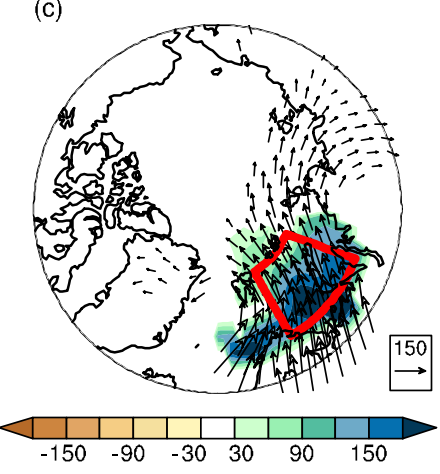

(d)

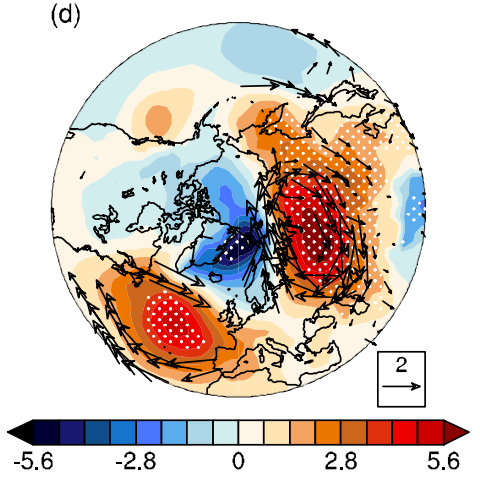

(b)

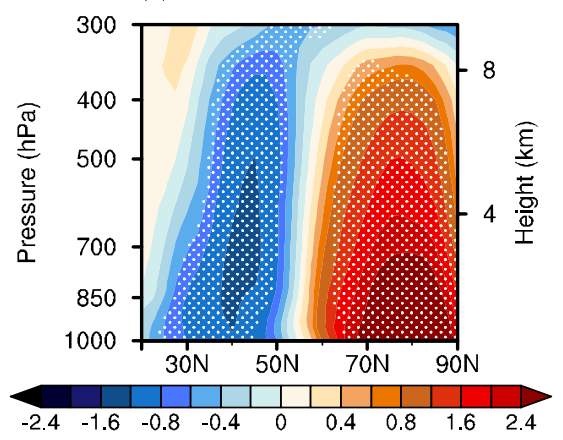

Fig. 1 Composites of winter a SAT, $\mathbf{b}$ vertical temperature averaged along $0^{\circ}-150^{\circ} \mathrm{E}$, $\mathbf{c}$ water vapor transport vertically intergrated from 1000 to $300 \mathrm{hPa}$ (vectors; $\mathrm{kg} \mathrm{m}^{-1} \mathrm{~s}^{-1}$ ) and corresponding magnitude anomalies (shading), d SLP (shading) and UV850 (vectors), e Z300, between the high and low ARTI_2m years during 1982-2013 from ERA-I. Dotted values and vectors exceed the $95 \%$ confidence level. Dotted values and vectors exceed the 95\% confidence level. c Shaded values exceed the $95 \%$ confidence level 
warming is likely a driver of Eurasian cooling through its influence on the downstream trough, the background temperature gradient and the polar jet stream (Kim et al. 2014; Mori et al. 2014; Screen 2017c). Meanwhile, moisture intrusion into the Arctic from lower latitudes through atmospheric circulation anomalies, is an important driver of Arctic warming by reinforcing the downward infrared radiation (IR) (Kim et al. 2017; Luo et al. 2017; Park et al. 2015; Zhang et al. 2008). As indicated by Fig. $1 \mathrm{~b}$ and c, coinciding with increased poleward moisture flux from the North Atlantic, the entire troposphere gets warmer over the Barents-Kara Seas and colder over East Asia, forming the deep Arctic warming-cold continent pattern (He et al. 2020).

Before investigating the physical factors determining the linkage between Arctic warming and East Asian winter temperature, it is necessary to compare the simulated Arctic-East Asian SAT relationship to the ERA-I. The regression coefficient of SAT over East Asia on the winter ARTI_2m during 1982-2013 is statistically significant in ERA-I $(-0.57)$, but close to zero in the multi-model ensemble mean of EXP1 (-0.09) and EXP2 (-0.02) (Fig. 2a, c). Individual models in both experiments can capture, but tend to underestimate the negative relationship between surface temperature over the Barents-Kara Seas and East Asia (Fig. 2a, c). The simulated multi-model ensemble-mean cold anomalies at midlatitudes, associated with warming in the Barents-Kara Seas, are less significant in both experiments (Fig. 3a, d). One particular highlight in this paper, is the revelation of the dramatic inter-ensemble diversity for individual models in simulating the Arctic-East Asian SAT relationship. The standard deviation of inter-ensemble variability for individual models in EXP1 is between 0.14 and 0.23 (Fig. 2a). In more detail, as illustrated by Fig. 2 b, the regression coefficients among ensemble members of individual models in EXP1 range from -0.83 to -0.11 in CAM $4,-0.78$ to -0.08 in WACCM, -0.58 to 0.08 in IFS, -0.49 to 0.07 in IAP4, -0.57 to 0.12 in LMDZOR, and -0.74 to -0.11 in AFES. There also exists large spread among ensemble members of individual models in EXP2 (Fig. 2d) due to the random (a) EXP1

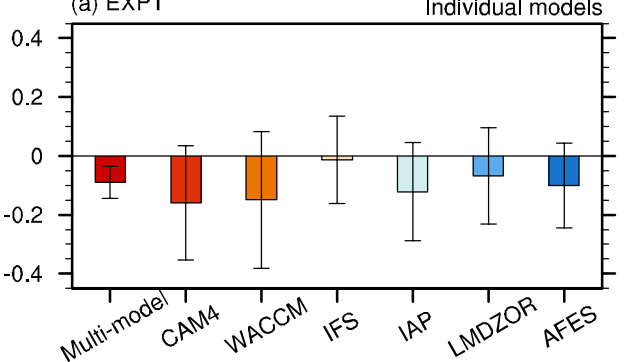

(c) EXP2

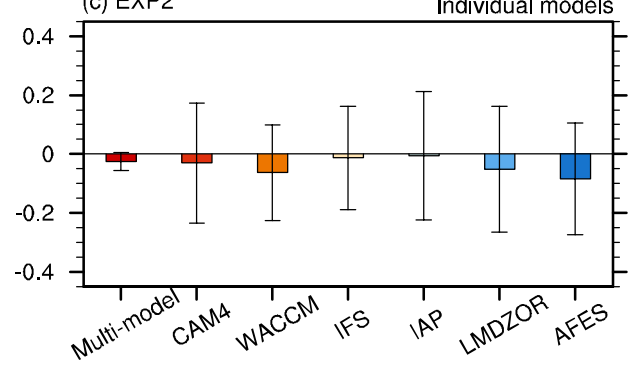

(e) EXP1 minus EXP2

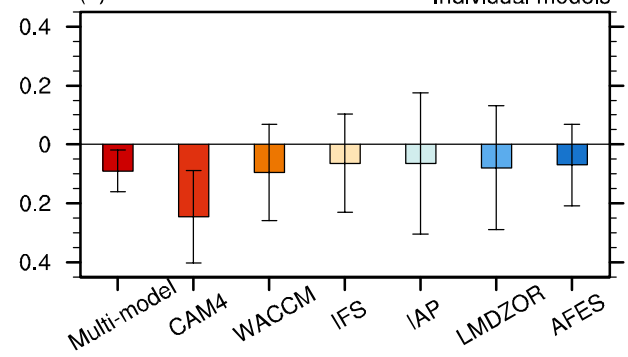

(b) EXP1

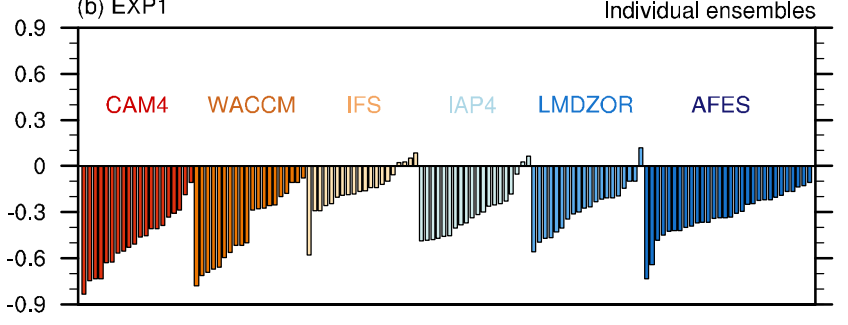

(d) EXP2

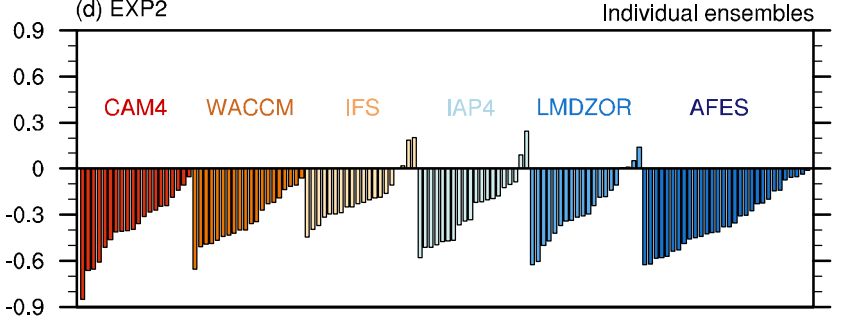

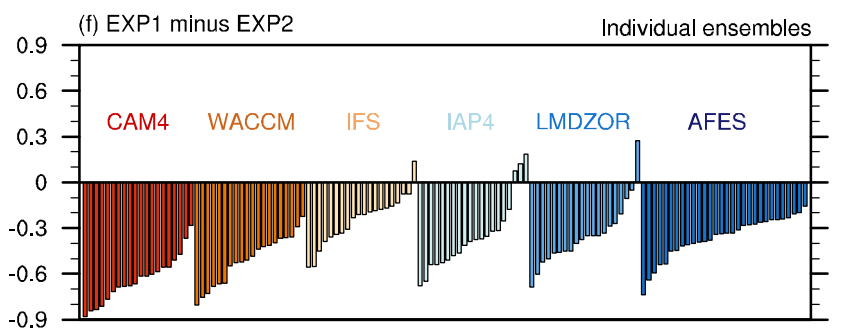

Fig. 2 Regression coefficients of winter SAT over East Asia (EAT_2m) against the Arctic surface temperature index (ARTI_2m) during 1982-2013, from a multi-model ensemble mean and individual models, and $\mathbf{b}$ individual ensemble members, in EXP1. a The

error bars denote the standard deviation of inter-model variability and inter-ensemble variability for individual models. c, $\mathbf{d}$ And e, $\mathbf{f}$ same as $\mathbf{a}, \mathbf{b}$, but for $\mathbf{c}, \mathbf{d}$ EXP2 and e, f EXP1-minus-EXP2, respectively 
(a) EXP1
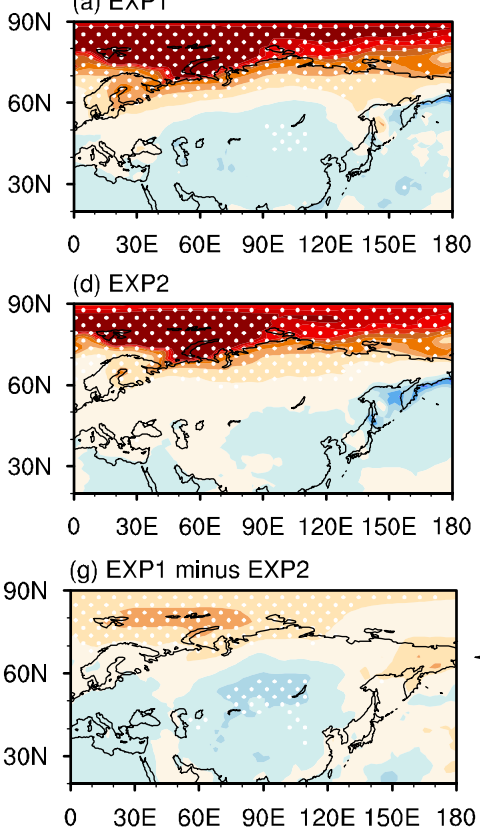

(h) EXP1
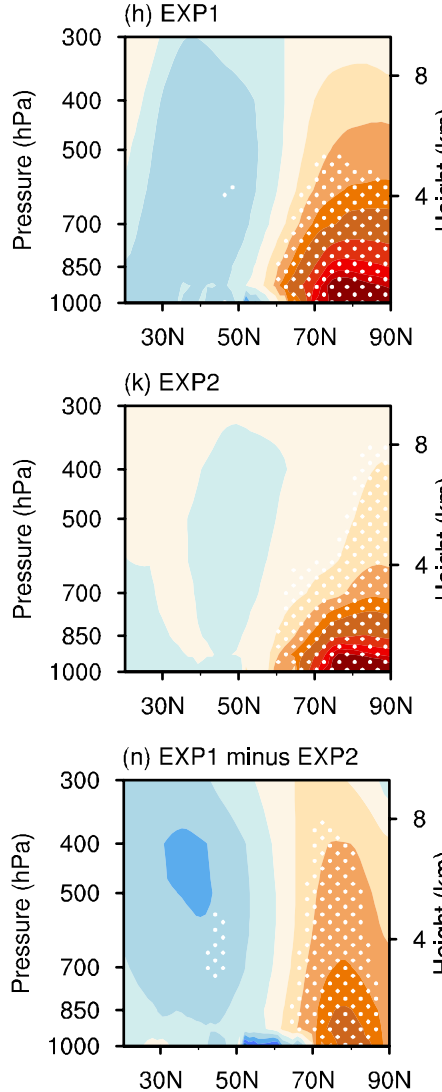

(b) EXP1_10\%high

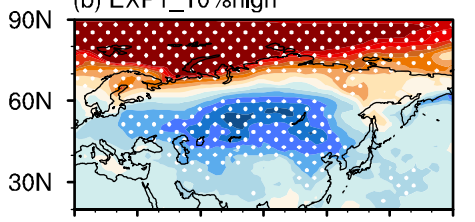

030 E 60 E 90 E 120 E 150 E 180

$90 \mathrm{~N}$ (e) EXP2_10\%high

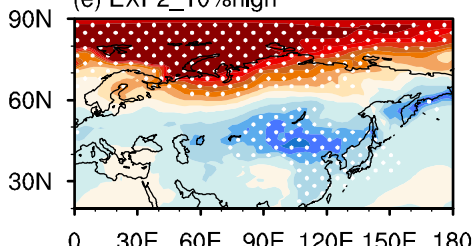

(c) EXP1_10\%low

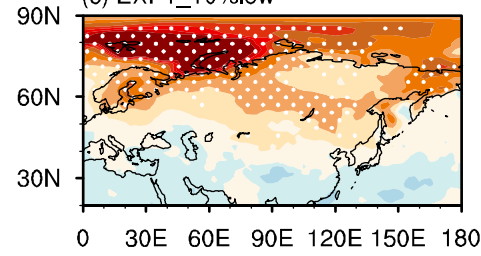

(f) EXP2_10\%low

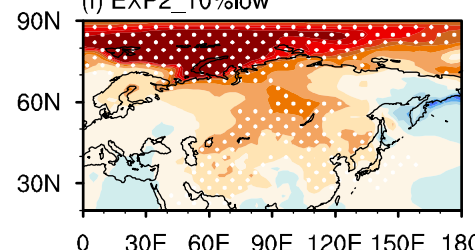

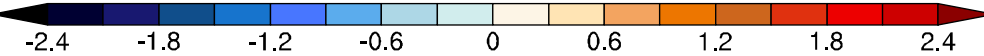
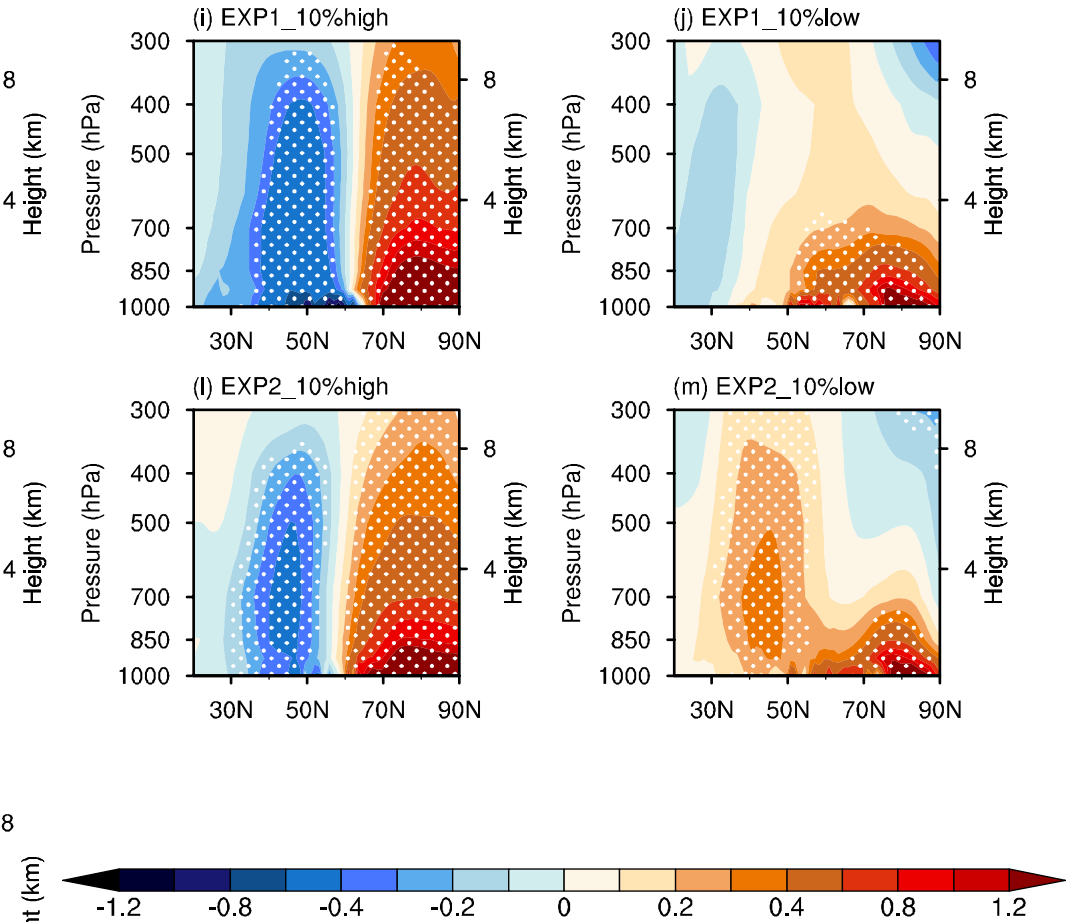

Fig. 3 a-c Composites of winter SAT between the high and low ARTI_2m years during 1982-2013, from the multi-model ensemble mean of a EXP1, b 10\% high-ensemble in EXP1 and c 10\% lowensemble in EXP1. d-f Same as a-c, but for EXP2. g Same as a, but for EXP1-minus-EXP2. h-n Same as $\mathbf{a}-\mathbf{g}$, but for vertical temperature averaged along $0^{\circ}-150^{\circ} \mathrm{E}$. The dotted values exceed the $95 \%$ confidence level 
superposition of the forced and internal components of SAT.

To clarify the large uncertainty in model simulations, we select the top $10 \%$ highest-regression ensemble members (10\% high-ensemble) and the $10 \%$ lowest-regression ensemble members ( $10 \%$ low-ensemble) for each model and then take an average across the models, comparing the difference between them. Associated with the ARTI_2m, significant warm anomalies over the Barents-Kara Seas and cold anomalies over Eurasia (including East Asia) are reproduced by the EXP1_10\% high-ensemble (Fig. 3b). Cold anomalies in EXP2_10\% high-ensemble shift more eastward than those in EXP1_10\% high-ensemble, dominated over East Asia (Fig. 3e). As expected, EXP1/EXP2_10\% low-ensemble captures almost no negative SAT anomalies over midlatitudes, though the Arctic surface is significantly warmer (Fig. 3c, f). Differences in simulating the linkage between Arctic warming and East Asian winter climate by the same model with different initial conditions suggest the important role of atmospheric internal variability.

The oceanic influence is further estimated from the difference between EXP1 and EXP2 [referred to as EXP1-minusEXP2; Xu et al. (2020)]. For example, CAM4 simulations in EXP1-minus-EXP2 are obtained by subtracting the ensemble mean of CAM4 in EXP2 from each member of CAM4 in EXP1. The composite SAT difference between the high and low ARTI_2m years in the multi-model ensemble mean of EXP1-minus-EXP2 is also shown (Fig. 3g), characterized by the significant warm Arctic-cold continent anomaly pattern though underestimated compared to ERA-I. The multi-model ensemble mean reduces the amplitude of internal variability compared to prescribed forcing. Therefore, results from EXP1-minus-EXP2 make clear that the linkage between Arctic warming and East Asian winter climate can also be driven by SST, in part.

An insightful way to understand the warm Arctic-cold continent connection is to explore the mechanism of Arctic warming, which has been demonstrated related to Arctic sea ice decline (Screen and Simmonds 2010) and moisture intrusion (Woods and Caballero 2016) but still remains incomplete. In Fig. 4, we compare the simulated vertically integrated water vapor transport associated with the ARTI_2m between the $10 \%$ high- and $10 \%$ low-ensemble and between different boundary conditions. Note that only five models are employed when describing the moisture flux, due to the lack of specific humidity data in AFES. But it would make no difference (Figure not shown) since no systematical deviation is found between the results from AFES and the other five models (Koenigk et al. 2018). As shown in Fig. 4a-c, significant increase of poleward moisture transport is present in EXP1, which is stronger in 10\% high-ensemble but absent in $10 \%$ low-ensemble. Poleward heat flux which amplifies Arctic warming (Jang et al. 2019; Kim et al. 2017) accompanies with poleward moisture flux (Skific and Francis 2013). Warm and moist air intrusion into the Arctic enhances the downward IR which is an important warming agent in the Arctic (Park et al. 2015). In this sense, remote moisture transport into the Arctic would contribute to a warmer Arctic in EXP1 and EXP1_10\% high-ensemble (Fig. 3a, b). It should be noted that no significant increase of poleward moisture transport is detected in EXP1_10\% low-ensemble (Fig. 4c), but significant warmer anomalies (greater than $2.4{ }^{\circ} \mathrm{C}$ ) are still over the Arctic surface (Fig. 3c). One key finding is that the main difference between the $10 \%$ highand $10 \%$ low-ensemble of EXP1 appears in the vertical structure of Arctic warming (Fig. 3i vs. j). In EXP1_10\% high-ensemble, the Arctic shows significantly warmer anomalies throughout the troposphere, with maximum values near the surface and reduced amplitude in the mid- and uppertroposphere (Fig. 3i). By contrast, Arctic warmer anomalies in EXP1_10\% low-ensemble are absent in the upper level but confined to the lower troposphere (under $700 \mathrm{hPa}$ ) (Fig. 3j). The Arctic-averaged $\left(70^{\circ}-80^{\circ} \mathrm{N}, 30^{\circ}-70^{\circ} \mathrm{E}\right)$ warm anomaly at $500 \mathrm{hPa}$ is $0.7^{\circ} \mathrm{C}$ and $0.1{ }^{\circ} \mathrm{C}$ in the $10 \%$ high- and $10 \%$ low-ensemble, respectively (Fig. 5a vs. b). The difference in Arctic warming aloft between the 10\% high- and 10\% low-ensemble is also well represented in the vertical thickness of the layer between 850 and $300 \mathrm{hPa}$ (Fig. 5e vs. f). This strongly suggests that the warm and moist air intrusion from lower latitudes into the Barents-Kara Seas contribute more to Arctic warming aloft than to surface warming. In EXP2, poleward moisture transport is much weaker and less significant than that in EXP1 (Fig. 4d) and Arctic warm anomalies larger than $0.2^{\circ} \mathrm{C}$ are trapped in the lower troposphere (Fig. 3k). Consistent with EXP1, distinct difference of the water vapor transport and vertical structure of Arctic warming between the 10\% high- and 10\% low-ensemble can also be obtained from EXP2 (Figs. 31 vs. m, 4e vs. f, 5c vs. d, g vs. h). But the composite difference of Arctic sea ice between the high and low ARTI_2m years shows significantly negative anomalies over the Barents-Kara Seas in both 10\% high-ensemble and 10\% low-ensemble (Fig. 6). Negligible difference in sea ice reduction (Fig. 6) coincides exactly with the negligible difference in Arctic surface warming (Fig. 3b, c, e, f), underlining that Arctic surface warming is primarily a manifestation of sea-ice melting but warming aloft is not mainly attributable to sea-ice melting.

Zhong et al. (2018) evaluated the local and external moisture contribution to Arctic warming. In this analysis, we further distinguish the role of moisture flux in deep Arctic warming versus shallow Arctic warming based on the results of EXP1, EXP2, and EXP1-minus-EXP2. In both EXP1 and EXP2, significantly increased evaporation is observed over the Barents-Kara Seas (Fig. 7a, b), which is driven by local boundary forcing (Screen and Simmonds 2010). But the evaporation anomaly in EXP2 is invisible 
(a) EXP1

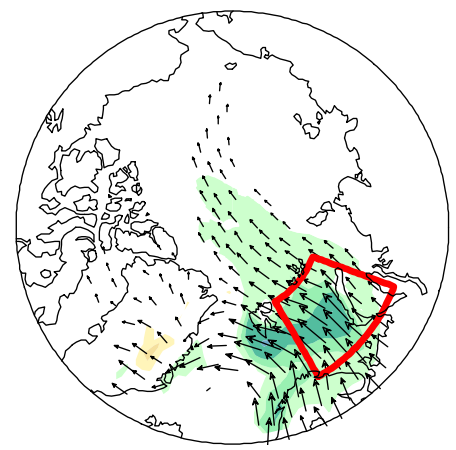

(d) EXP2

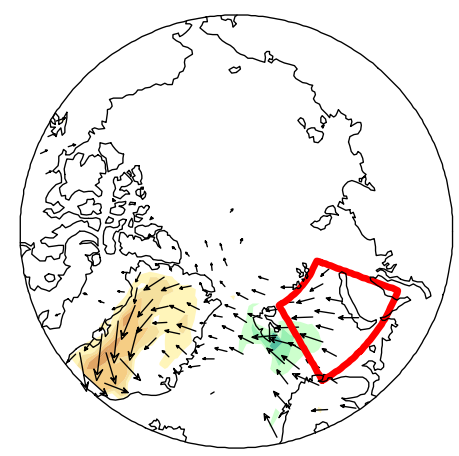

(b) EXP1_10\%high

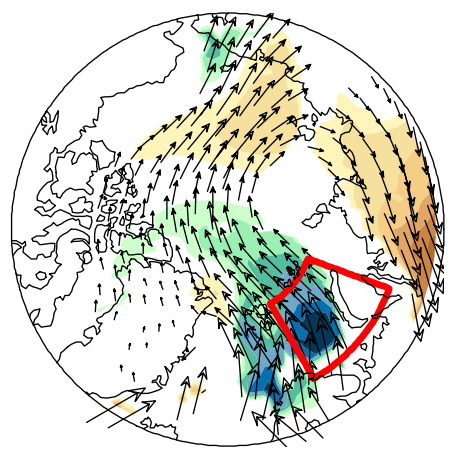

(e) EXP2_10\%high

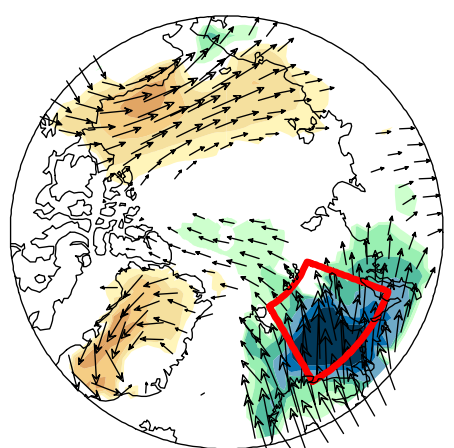

(c) EXP1_10\%low

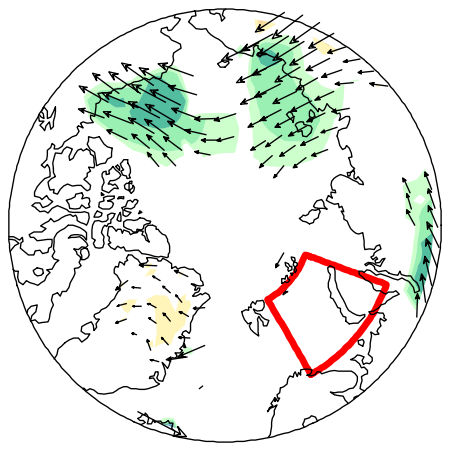

(f) EXP2_10\%low

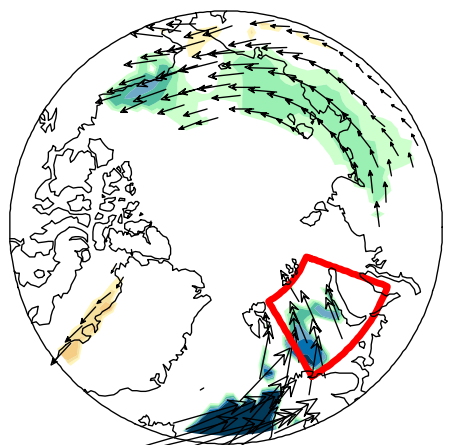

(g) EXP1 minus EXP2

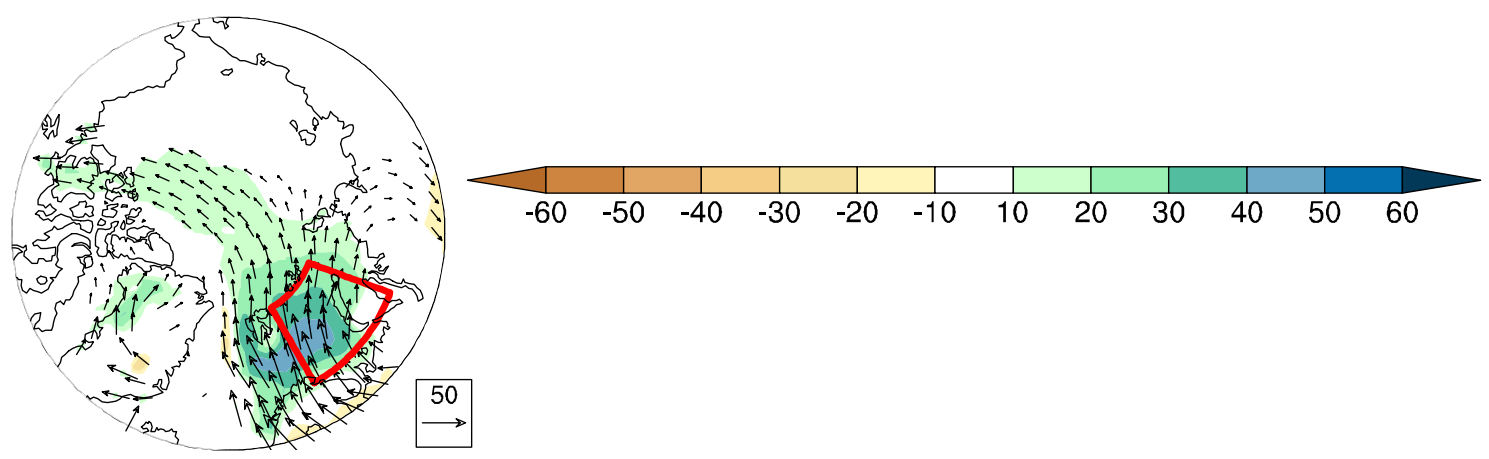

Fig. 4 a-c Composites of winter water vapor transport vertically intergrated from 1000 to $300 \mathrm{hPa}$ (vectors; $\mathrm{kg} \mathrm{m}^{-1} \mathrm{~s}^{-1}$ ) and corresponding magnitude anomalies (shading), between the high and low ARTI_2m years during 1982-2013, from the multi-model (AFES is

outside the Arctic (Fig. 7b), consistent with weak poleward moisture intrusion (Fig. 4d). When sea ice forcing is excluded in EXP1-minus-EXP2, this experiment captures a weak evaporation anomaly over the Barents-Kara Seas but increased evaporation over the Norwegian Sea and midlatitude North Atlantic (Fig. 7c), associated with enhanced external moisture intrusion (Fig. 4g). That is, moisture increase over the Barents-Kara Seas originates primarily from, local evaporation in EXP2, and remote moisture intrusion in EXP1-minus-EXP2. Note that Arctic mid- and upper-tropospheric warming in EXP1-minus-EXP2 is still omitted) ensemble mean of a EXP1, b 10\% high-ensemble in EXP1 and $\mathbf{c} 10 \%$ low-ensemble in EXP1. d-f Same as a-c, but for EXP2. $\mathbf{g}$ Same as a, but for EXP1-minus-EXP2. The vectors and shaded values exceed the $95 \%$ confidence level

comparative to that in EXP1, but near-surface warming is substantially weakened in EXP1-minus-EXP2 (Fig. 3h vs. $\mathrm{n}$ ). It highlights that poleward moisture transport from the Norwegian Sea and midlatitude North Atlantic plays a major role in Arctic warming aloft through downward IR, while surface warming seems to be induced by sea ice melting, which is sustained by positive feedback processes related to local evaporation. The poleward moisture intrusion and Arctic sea ice decline in combination can drive the surface-amplified deep Arctic warming throughout the troposphere. 
Fig. 5 Composites of winter a-d vertical temperature averaged along $30^{\circ}-70^{\circ} \mathrm{E}$ between the high and low ARTI_2m years during 1982-2013, from the a $10 \%$ high-ensemble in EXP1 and b 10\% low-ensemble in EXP1. c, d Same as a, b, but for EXP2. e-h Same as a-d, but for $850-300 \mathrm{hPa}$ thickness. The dotted values exceed the $95 \%$ confidence level
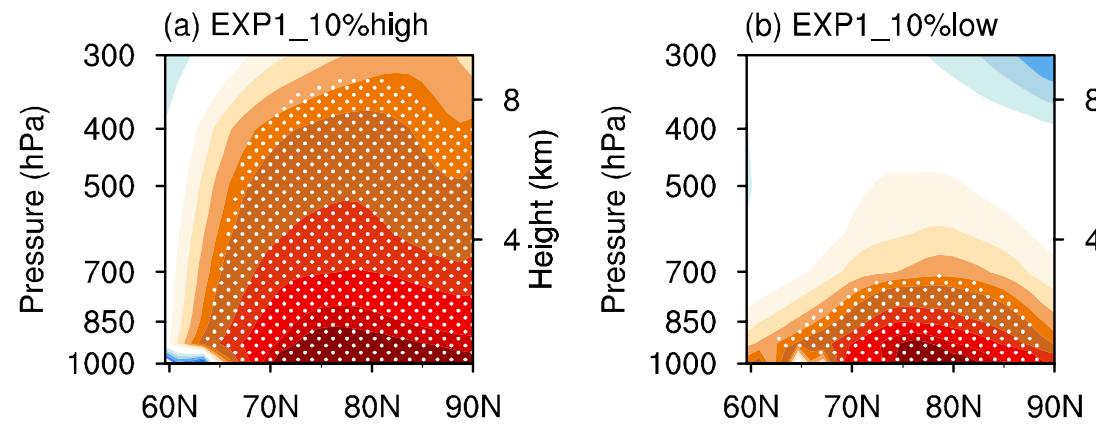

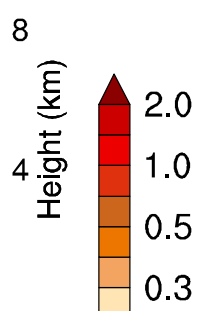

(c) EXP2_10\%high

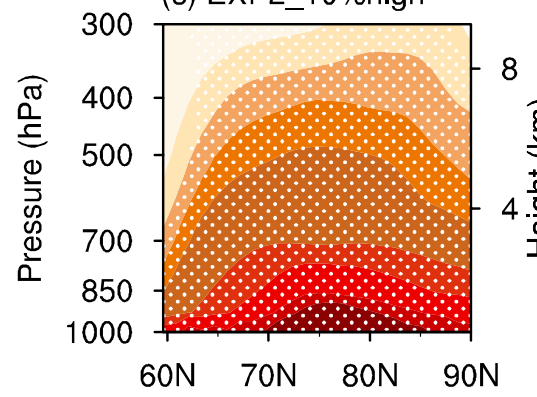

(d) EXP2_10\%low

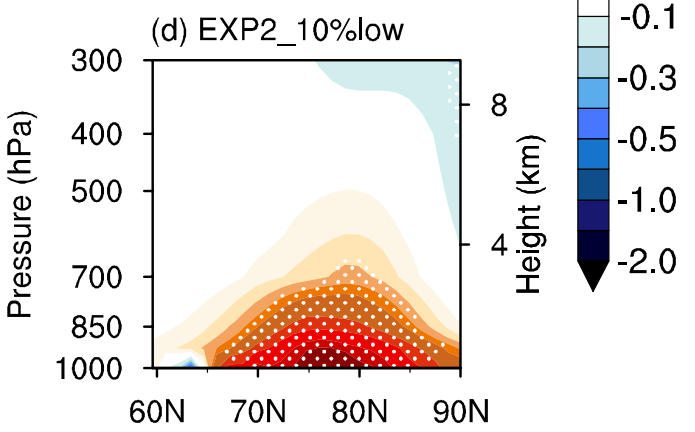

(e) EXP1_10\%high

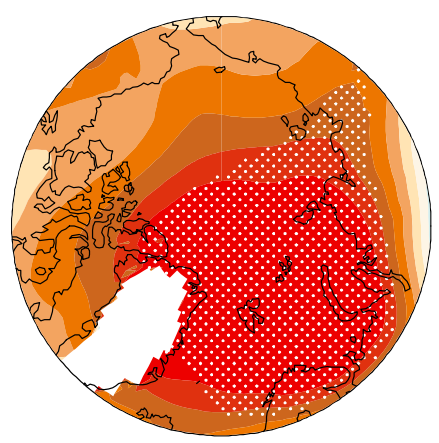

(g) EXP2_10\%high

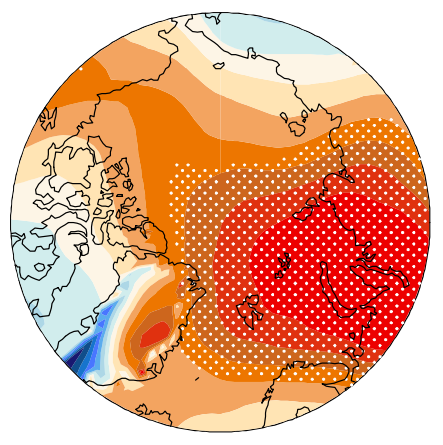

(f) EXP1_10\%low

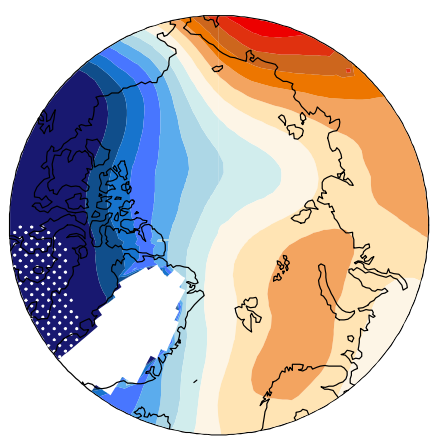

(h) EXP2_10\%low

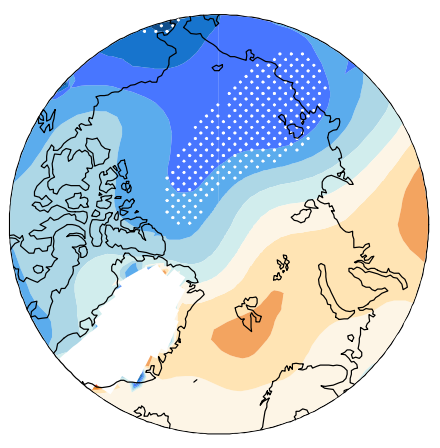

5

0

$-5$ $-10$ $-15$

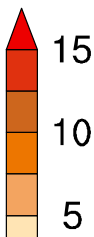

In addition, the Eurasian winter temperature anomalies are different when the Arctic troposphere is significantly warmer or not. As illustrated by Fig. 3i and 1, midlatitude Eurasia shows significant colder anomalies at both the surface and troposphere in EXP1/EXP2_10\% high-ensemble, concurrent with deep Arctic warming extending throughout the troposphere. The vertical structure of the significantly warm Arctic-cold continent pattern is also reproduced by EXP1-minus-EXP2 with a weaker magnitude (Fig. 3n). On the contrary, no colder conditions are observed at midlatitudes associated with shallow Arctic warming limited to the lower troposphere in EXP1/EXP2_10\% low-ensemble (Fig. 3j, m). Thus, this result clearly suggests that Eurasian cold conditions occur more often in deep Arctic warming 
(a) EXP1_10\%high

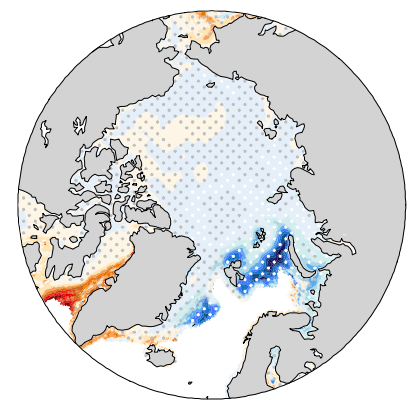

(b) EXP1_10\%low

(c) EXP2_10\%high

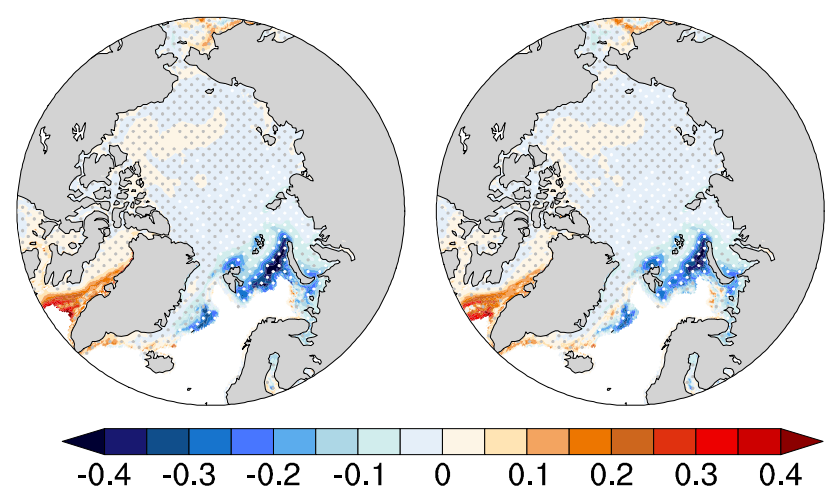

Fig. 6 Composites of winter sea ice concentration between the high and low ARTI_2m years during 1982-2013, from the a 10\% highensemble in EXP1 and b $10 \%$ low-ensemble in EXP1. c, d Same as a, b, but for EXP2. The dotted values exceed the 95\% confidence level

winters rather than shallow Arctic warming winters, consistent with the recent research (He et al. 2020; Jang et al. 2019; Labe et al. 2020; Xu et al. 2019). Furthermore, the peaking of Arctic warming aloft leads the maximum decrease of
Eurasian temperature by approximately 3 days on synoptic scale (He et al. 2020). This reinforces the point that the vertical structure of Arctic warming should be taken seriously when investigating the linkage between Arctic warming and Eurasian winter climate.

To shed further light on the relationship revealed above, we present the composited analyses of large-scale atmospheric circulations between the high and low ARTI_2m winters in Fig. 8. The significant deep Arctic warming-cold continent pattern throughout the troposphere in EXP1/ EXP2_10\% high-ensemble is associated with an increase of SLP from the coastal Barents-Kara region to the Siberian region, indicating an enhancement of the Siberian high (Fig. 8b, e). This anomalous circulation is a quasi-equivalent barotropic pattern, accompanied with mid-tropospheric ridging near the Ural Mountains and downstream cold trough over East Asia (Fig. 8i, 1). As both a consequence and driver of the deep Arctic warming (Screen 2017a), the anticyclone flow favors cold intrusion from the Arctic to midlatitudes along the east flank and warm and moist air intrusion into the Arctic along the west flank. He et al. (2020) indicated the interaction between the deep Arctic warming and Ural blocking based on lead-lag analysis in CMIP5 historical simulations. The causality between them, of course, needs to be further investigated. The Ural blocking ridge also amplifies the EAWM through propagation of the quasi-stationary Rossby wave (Cheung et al. 2012; Cohen et al. 2014; Takaya and Nakamura 2005; Zhou 2017). For the 10\% low-ensemble, there shows anomalous cyclonic flow near the Urals in EXP1 (Fig. 8c, j), which even occupies the Arctic region in EXP2 (Fig. 8f, m).

Ural blocking in combination with the positive phase of the North Atlantic Oscillation (NAO+) (Fig. 1d, e) has been considered as the most favorable circulation pattern (a) EXP1

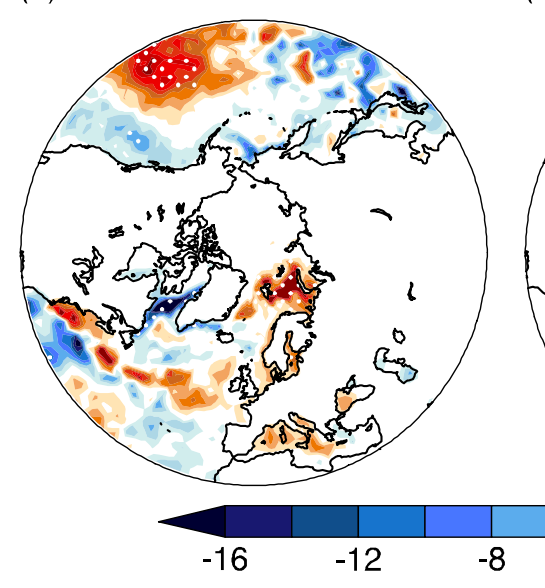

(b) EXP2

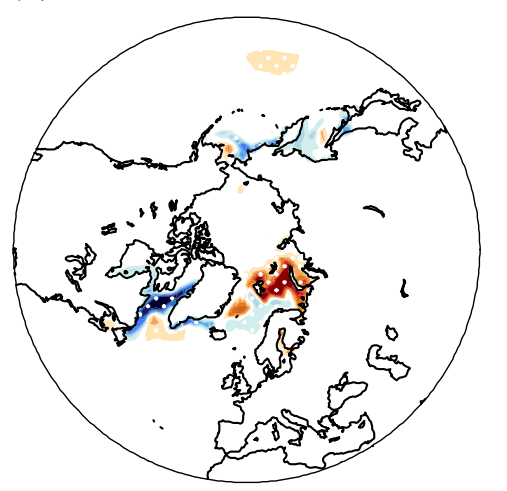

\section{(c) EXP1 minus EXP2}

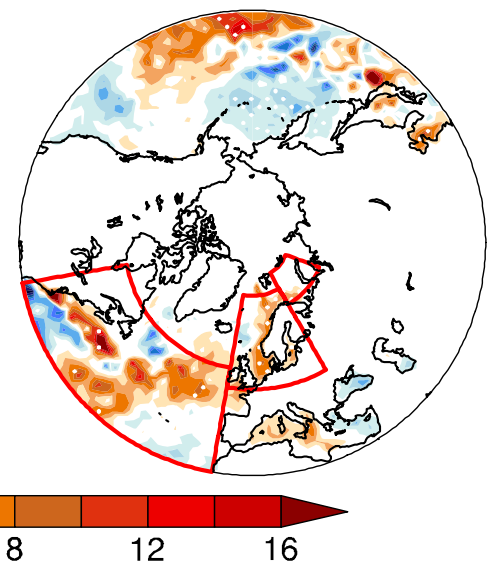

Fig. 7 Composite of winter evaporation anomalies multiplied by 28.5 $\left(1 \mathrm{~mm} \mathrm{~d}^{-1}=28.5 \mathrm{~W} \mathrm{~m}^{-2}\right.$ ) between the high and low ARTI_2m years during 1982-2013, from the multi-model ensemble mean of a EXP1, b EXP2, and c EXP1-minus-EXP2. The dotted values exceed the 95\% confidence level 


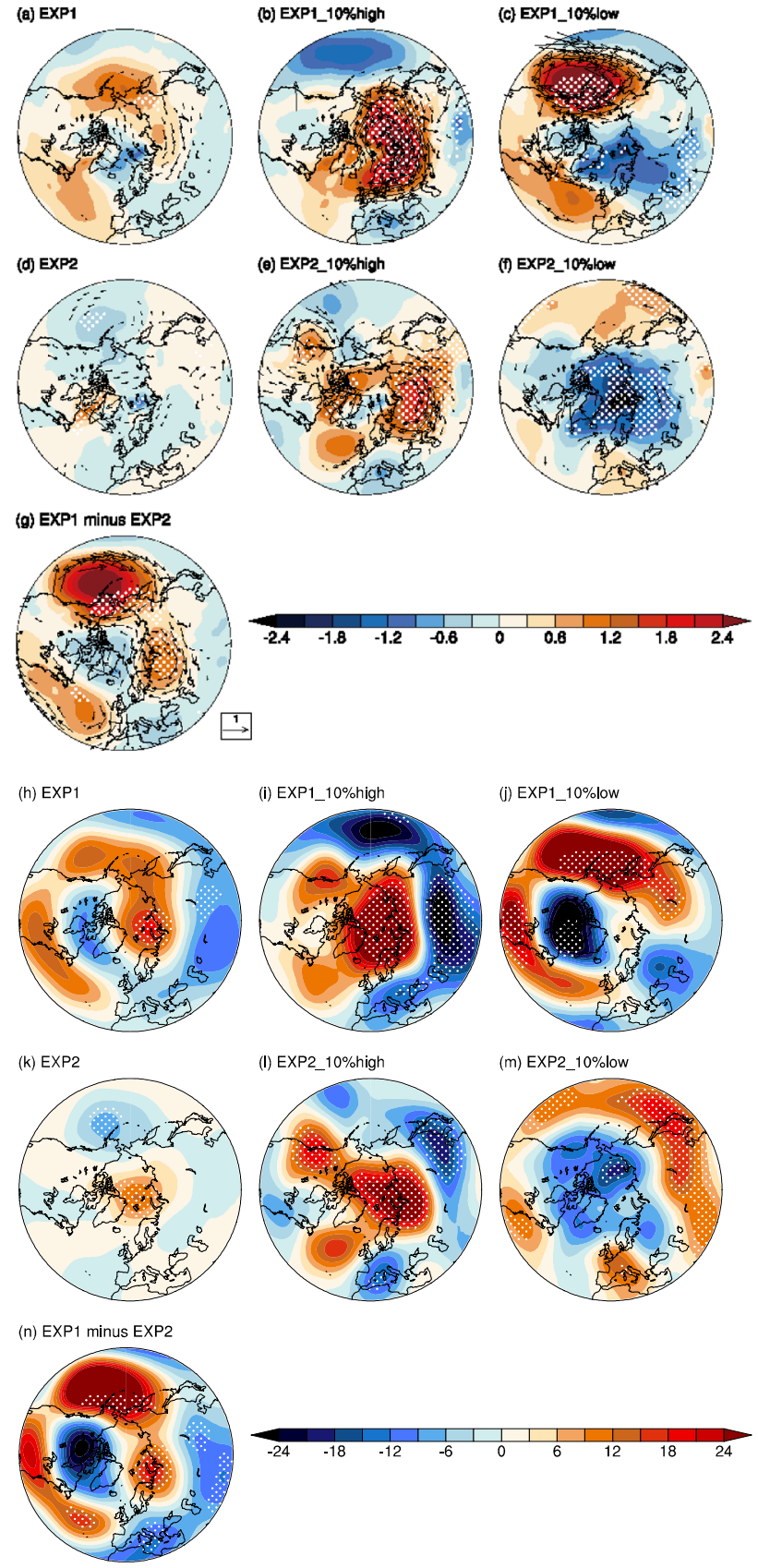

Fig. 8 a-c Composites of winter SLP (shading) and UV850 (vectors) between the high and low ARTI_2m years during 1982-2013, from the multi-model ensemble mean of a EXP1, b 10\% high-ensemble in EXP1 and c 10\% low-ensemble in EXP1. d-f Same as a-c, but for EXP2. g Same as a, but for EXP1-minus-EXP2. h-n Same as a-g, but for Z300. The vectors and dotted values exceed the $95 \%$ confidence level

that promotes moisture intrusion into Barents-Kara Seas from the mid-latitude North Atlantic (Luo et al. 2017). In EXP1, together with an anticyclone near the Barents-Kara Seas and Urals, the upstream atmospheric circulation pattern in the North Atlantic resembles the NAO+ (Fig. 8h), which

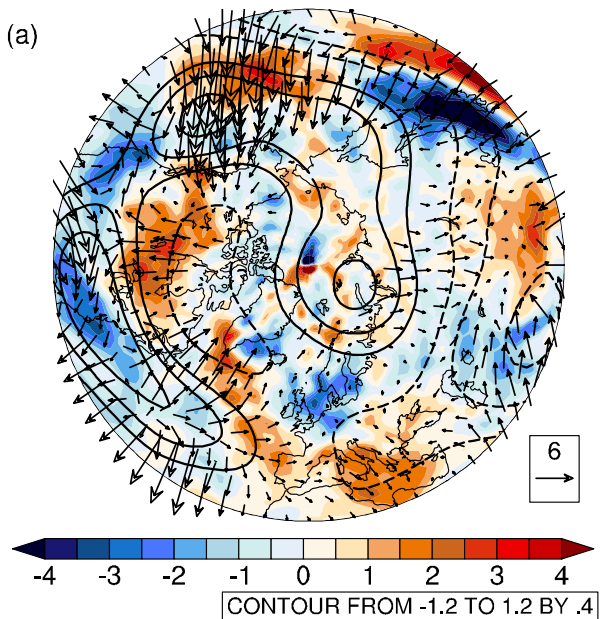

(b)
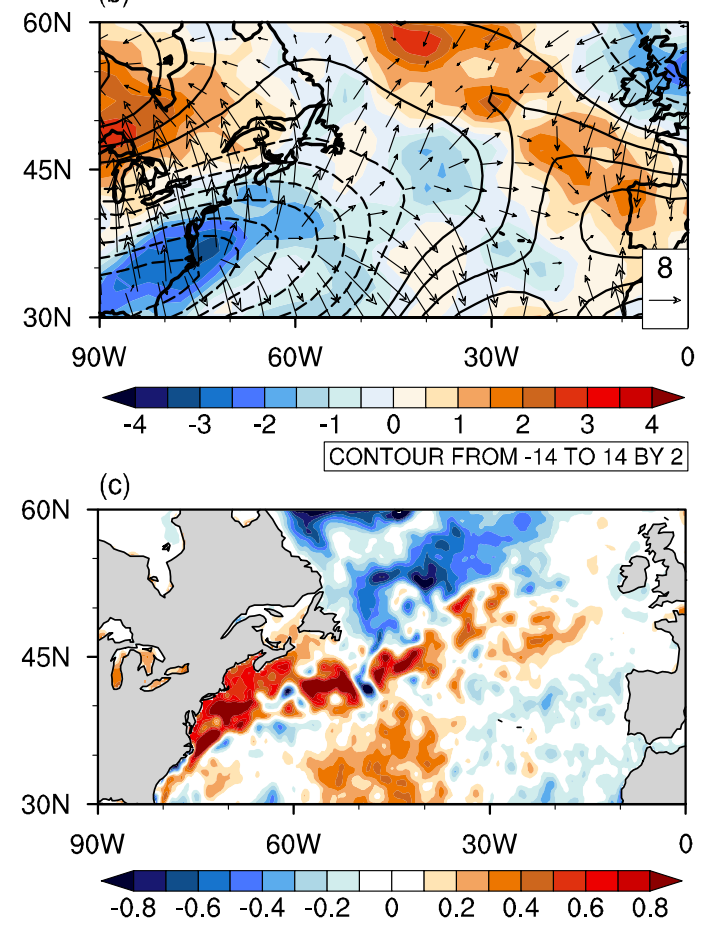

Fig. 9 Composite of winter a Rossby wave sources (shading; $10^{-11} \mathrm{~s}^{-2}$ ), quasi-geostrophic streamfunction (contours; $10^{6} \mathrm{~m}^{2} \mathrm{~s}^{-1}$ ) and the associated wave active flux (vectors; $10^{-2} \mathrm{~m}^{2} \mathrm{~s}^{-2}$ ) at $300 \mathrm{hPa}$, b Rossby wave sources (shading; $10^{-11} \mathrm{~s}^{-2}$ ), velocity potential (contours; $10^{4} \mathrm{~m}^{2} \mathrm{~s}^{-1}$ ) and divergent wind (vectors; $10^{-2} \mathrm{~m} \mathrm{~s}^{-1}$ ) at $300 \mathrm{hPa}$, and $\mathbf{c}$ SST between the high and low ARTI_2m years during 1982-2013 from the multi-model ensemble mean of EXP1

is more conspicuous in EXP1-minus-EXP2 (Fig. 8n). The wave train structure composed of the NAO+, Ural blocking and East Asian trough is primarily excited by an anomalous Rossby wave source in the upper troposphere over the North Atlantic and propagates to East Asia through Greenland (Fig. 9a). Positive SST anomalies in the North Atlantic near the Gulf Stream Extension might induce the upper-level anomalous divergent wind and Rossby wave source (Fig. 9b, 
c) (Sato et al. 2014). Spanning the Atlantic and Eurasia, the wave train not only steers the pathway of moisture into the Barents-Kara Seas and intensifies Arctic warming aloft, but also promotes the linkage between the Arctic and Eurasian climate (Luo et al. 2016) (Fig. 3g, n). The wave train propagating from the North Pacific to the Arctic and Eurasia is weaker compared to that from the North Atlantic. It is therefore concluded the processes associated with the deep Arctic warming may be related to the forcing of remote SST (Fig. 3n), especially if there is favorable atmospheric circulation such as Rossby wave train propagating from the North Atlantic into the Arctic (Fig. 8n). Also, the deep Arctic warming-cold continent pattern in EXP1-minus-EXP2 is vertically tilted (Fig. 3n), which might have a large implication to understand the dynamical process.

In EXP2, large-scale circulation changes are weak in the Eurasia-North Atlantic sector, except for the anticyclonic flow in the Arctic (Fig. 8k). The dramatic influence of Arctic sea ice decline on surface warming has been suggested in early studies and further verified by the results of EXP2 in this study, but its influence on the midlatitude climate has increasingly become a controversial issue (Screen et al. 2018). The simulated results in this study suggest that sea ice is not the major driver of the deep Arctic warming-cold continent pattern. As shown by Fig. 2d, most of the total 130 members in EXP2 (e.g. all ensemble members of CAM4, WACCM and AFES) can reproduce the negative SAT relationship between the Barents-Kara Seas and East Asia, despite the dramatic inter-ensemble diversity for individual models. In this sense, we can't assuredly deny the potential effect of Arctic sea ice loss which might also be overwhelmed by internal variability. Furthermore, the missing/weakening of the Arctic tropospheric warming in uncoupled AGCM can be due to its disability to capture the ocean-atmosphere interaction (Sorokina et al. 2016). And the atmospheric response to Arctic sea ice loss is sensitive to the background climate state (Screen and Francis 2016). Moreover, models differ in resolving the stratospheric processes (such as stratospheric polar vortex) and stratosphere-troposphere coupling that are important in the linkage between Arctic warming and midlatitude climate (Sun et al. 2015).

\section{Conclusions}

In this study, we use two sets of coordinated multi-model ensemble experiments (EXP1 and EXP2) to investigate the linkage between Arctic warming and East Asian cold winters and contributors to the linkage. There exists dramatic inter-ensemble diversity for individual models in simulating the relationship. The top 10\% highest-regression ensemble members ( $10 \%$ high-ensemble) can reproduce the observed deep Arctic warming-cold continent pattern which extends from surface to upper troposphere. But the $10 \%$ lowestregression ensemble members (10\% low-ensemble) capture shallow Arctic warming and no cold anomalies at midlatitudes. This indicates the important role of atmospheric internal variability in the Arctic-midlatitude linkage.

The mechanisms of deep Arctic warming and shallow Arctic warming are further explored. On the one hand, increased northward moisture transport from the Norwegian Sea and midlatitude North Atlantic into the Barents-Kara Seas plays a major role in Arctic warming aloft. On the other hand, Arctic surface warming is primarily induced by sea ice melting, which is sustained by positive feedback processes related to local evaporation. The poleward moisture intrusion and Arctic sea ice decline in combination can drive the surface-amplified deep Arctic warming throughout the troposphere.

These processes associated with the deep Arctic warming may be related to the forcing of remote SST, which is attributed to favorable atmospheric circulation such as Rossby wave train propagating from the North Atlantic. Based on the current analysis, sea ice reduction may not be the major driver of the deep Arctic warming-cold continent pattern.

Acknowledgements This research was supported by the National Natural Science Foundation of China (Grants 41991280, 42088101, 42025502, 41875118, and 42075030), the National Key R\&D Program of China (2016YFA0600703), the Young Talent Support Program by China Association for Science and Technology (Grant 2016QNRC001), the CONNECTED supported by UTFORSK Partnership Program (UTF-2016-long-term/10030), Guangdong Major Project of Basic and Applied Basic Research (2020B0301030004), and the Startup Foundation for Introducing Talent of NUIST (2021r030).

Funding Open access funding provided by University of Bergen (incl Haukeland University Hospital).

Open Access This article is licensed under a Creative Commons Attribution 4.0 International License, which permits use, sharing, adaptation, distribution and reproduction in any medium or format, as long as you give appropriate credit to the original author(s) and the source, provide a link to the Creative Commons licence, and indicate if changes were made. The images or other third party material in this article are included in the article's Creative Commons licence, unless indicated otherwise in a credit line to the material. If material is not included in the article's Creative Commons licence and your intended use is not permitted by statutory regulation or exceeds the permitted use, you will need to obtain permission directly from the copyright holder. To view a copy of this licence, visit http://creativecommons.org/licenses/by/4.0/.

\section{References}

Årthun M, Eldevik T, Smedsrud LH, Skagseth $\emptyset$, Ingvaldsen RB (2012) Quantifying the influence of Atlantic heat on Barents Sea ice variability and retreat. J Clim 25:4736-4743

Balsamo G, Viterbo P, Beljaars A, Hurk BVD, Hirschi M, Betts AK, Scipal K (2009) A revised hydrology for the ECMWF model: 
verification from field site to terrestrial water storage and impact in the Integrated Forecast System. J Hydrometeorol 10:623-643

Chen J, Sun S (1999) Eastern Asian winter monsoon anomaly and variation of global circulation part I: a comparison study on strong and weak winter monsoon. Sci Atmos Sin 23:101-110

Cheung HN, Zhou W, Mok HY, Wu MC (2012) Relationship between Ural-Siberian blocking and the East Asian winter monsoon in relation to the Arctic Oscillation and the El Nino-Southern Oscillation. J Clim 25:4242-4257

Cohen JL, Furtado JC, Barlow MA, Alexeev VA, Cherry JE (2012) Arctic warming, increasing snow cover and widespread boreal winter cooling. Environ Res Lett 7:014007

Cohen J et al (2014) Recent Arctic amplification and extreme midlatitude weather. Nat Geosci 7:627-637

Cohen J et al (2020) Divergent consensuses on Arctic amplification influence on midlatitude severe winter weather. Nat Clim Change 10:20-29

Dai A, Luo D, Song M, Liu J (2019) Arctic amplification is caused by sea-ice loss under increasing $\mathrm{CO}_{2}$. Nat Commun 10:121

Dee DP et al (2011) The ERA-Interim reanalysis: configuration and performance of the data assimilation system. Q J R Meteorol Soc 137:553-597

Docquier D, Koenigk T, Fuentes-Franco R, Karami MP, Ruprich-Robert Y (2021) Impact of ocean heat transport on the Arctic sea-ice decline: a model study with EC-Earth3. Clim Dyn. https://doi.org/ 10.1007/s00382-020-05540-8

Dong X, Xue F, Zhang H, Zeng Q (2012) Evaluation of surface air temperature change over China and the globe during the twentieth century in IAP AGCM4.0. Atmos Ocean Sci Lett 5:435-438

Fetterer F, Knowles K, Meier W, Savoie M, Windnagel AK (2017) Updated daily. Sea ice index, version 3. [indicate subset used]. Boulder, Colorado USA. NSIDC: National Snow and Ice Data Center. https://doi.org/10.7265/N5K072F8

Francis JA (2017) Why are Arctic linkages to extreme weather still up in the air? Bull Am Meteorol Soc 98:2551-2557

Gao Y et al (2015) Arctic sea ice and Eurasian climate: a review. Adv Atmos Sci 32:92-114

Graversen RG, Mauritsen T, Tjernström M, Källén E, Svensson G (2008) Vertical structure of recent Arctic warming. Nature 451:53-56

He S, Wang H (2012) An integrated East Asian winter monsoon index and its interannual variability. Chin J Atmos Sci 36:523-538

He S, Knudsen EM, Thompson DWJ, Furevik T (2018) Evidence for predictive skill of high-latitude climate due to midsummer sea ice extent anomalies. Geophys Res Lett 45:9114-9122

He S, Xu X, Furevik T, Gao Y (2020) Eurasian cooling linked to the vertical distribution of Arctic warming. Geophys Res Lett 47:e2020GL087212

Honda M, Inoue J, Yamane S (2009) Influence of low Arctic sea-ice minima on anomalously cold Eurasian winters. Geophys Res Lett 36:L08707

Hourdin F et al (2013) Impact of the LMDZ atmospheric grid configuration on the climate and sensitivity of the IPSL-CM5A coupled model. Clim Dyn 40:2167-2192

Huang R, Zhou L, Chen W (2003) The progresses of recent studies on the variabilities of the East Asian monsoon and their causes. Adv Atmos Sci 20:55-69

Hurrell JW, Hack JJ, Shea D, Caron JM, Rosinski J (2008) A new sea surface temperature and sea ice boundary dataset for the Community Atmosphere Model. J Clim 21:5145-5153

Jang Y-S, Kug J-S, Kim B-M (2019) How well do current climate models simulate the linkage between Arctic warming and extratropical cold winters? Clim Dyn 53:4005-4018

Johnson NC, Xie S-P, Yu K, Li X (2018) Increasing occurrence of cold and warm extremes during the recent global warming slowdown. Nat Commun 9:1724
Kim BM et al (2014) Weakening of the stratospheric polar vortex by Arctic sea-ice loss. Nat Commun 5:4646

Kim B-M et al (2017) Major cause of unprecedented Arctic warming in January 2016: critical role of an Atlantic windstorm. Sci Rep 7:40051

Koenigk T, Brodeau L (2014) Ocean heat transport into the Arctic in the twentieth and twenty-first century in EC-Earth. Clim Dyn 42:3101-3120

Koenigk T, Fuentes-Franco R (2019) Towards normal Siberian winter temperatures? Int J Climatol 39:4567-4574

Koenigk T et al (2018) Impact of Arctic sea ice variations on winter temperature anomalies in northern hemispheric land areas. Clim Dyn 52:3111-3137

Kug JS, Jeong JH, Jang YS, Kim BM, Folland CK, Min SK, Son SW (2015) Two distinct influences of Arctic warming on cold winters over North America and East Asia. Nat Geosci 8:759-762

Kumar A, Perlwitz J, Eischeid J, Quan X, Xu T, Zhang T (2010) Contribution of sea ice loss to Arctic amplification. Geophys Res Lett 37:L21701

Labe Z, Peings Y, Magnusdottir G (2020) Warm Arctic, cold Siberia pattern: role of full Arctic amplification versus sea ice loss alone. Geophys Res Lett 47:e2020GL088583

Liu J, Curry JA, Wang H, Song M, Horton RM (2012) Impact of declining Arctic sea ice on winter snowfall. Proc Natl Acad Sci 109:4074-4079

Luo D, Xiao Y, Yao Y, Dai A, Simmonds I, Franzke CLE (2016) Impact of Ural blocking on winter warm Arctic-cold Eurasian anomalies. Part I: blocking-induced amplification. J Clim 29:3925-3947

Luo B, Luo D, Wu L, Zhong L, Simmonds I (2017) Atmospheric circulation patterns which promote winter Arctic sea ice decline. Environ Res Lett 12:054017

Marsh DR, Mills MJ, Kinnison DE, Lamarque JF, Calvo N, Polvani LM (2013) Climate change from 1850 to 2005 simulated in CESM1(WACCM). J Clim 26:7372-7391

Matsumura S, Kosaka Y (2019) Arctic-Eurasian climate linkage induced by tropical ocean variability. Nat Commun 10:3441

McCusker KE, Fyfe JC, Sigmond M (2016) Twenty-five winters of unexpected Eurasian cooling unlikely due to Arctic sea-ice loss. Nat Geosci 9:838-842

Meleshko VP, Johannessen OM, Baidin AV, Pavlova TV, Govorkova VA (2016) Arctic amplification: does it impact the polar jet stream? Tellus 68:32330

Mori M, Watanabe M, Shiogama H, Inoue J, Kimoto M (2014) Robust Arctic sea-ice influence on the frequent Eurasian cold winters in past decades. Nat Geosci 7:869-873

Mori M, Kosaka Y, Watanabe M, Nakamura H, Kimoto M (2019) A reconciled estimate of the influence of Arctic sea-ice loss on recent Eurasian cooling. Nat Clim Change 9:123-129

Neale RB, Richter J, Park S, Lauritzen PH, Vavrus SJ, Rasch PJ, Zhang M (2013) The mean climate of the Community Atmosphere Model (CAM4) in forced SST and fully coupled experiments. J Clim 26:5150-5168

Ogawa F et al (2018) Evaluating impacts of recent Arctic sea ice loss on the northern hemisphere winter climate change. Geophys Res Lett 45:3255-3263

Ohfuchi W et al (2004) 10-Km mesh meso-scale resolving global simulations of the atmosphere on the Earth simulator-preliminary outcomes of AFES (AGCM for the Earth simulator). J Earth Simulator 1:8-34

Overland JE, Wood KR, Wang M (2011) Warm Arctic-cold continents: climate impacts of the newly open Arctic Sea. Polar Res 30:157-171

Park H-S, Lee S, Son S-W, Feldstein SB, Yu K (2015) The impact of poleward moisture and sensible heat flux on Arctic winter sea ice variability. J Clim 28:5030-5040 
Perlwitz J, Hoerling M, Dole R (2015) Arctic tropospheric warming: causes and linkages to lower latitudes. J Clim 28:2154-2167

Reynolds RW, Smith TM, Liu C, Chelton DB, Casey KS, Schlax MG (2007) Daily high-resolution-blended analyses for sea surface temperature. J Clim 20:5473-5496

Sardeshmukh PD, Hoskins BJ (1988) The generation of global rotational flow by steady idealized tropical divergence. J Atmos Sci 45:1228-1251

Sato K, Inoue J, Watanabe M (2014) Influence of the Gulf Stream on the Barents Sea ice retreat and Eurasian coldness during early winter. Environ Res Lett 9:084009

Screen JA (2017a) Far-flung effects of arctic warming. Nat Geosci 10:253-254

Screen JA (2017b) The missing Northern European winter cooling response to Arctic sea ice loss. Nat Commun 8:14603

Screen JA (2017c) Simulated atmospheric response to regional and pan-Arctic sea ice loss. J Clim 30:3945-3962

Screen JA, Francis JA (2016) Contribution of sea-ice loss to Arctic amplification is regulated by Pacific Ocean decadal variability. Nat Clim Chang 6:856-860

Screen JA, Simmonds I (2010) The central role of diminishing sea ice in recent Arctic temperature amplification. Nature 464:1334-1337

Screen JA, Deser C, Simmonds I (2012) Local and remote controls on observed Arctic warming. Geophys Res Lett 39:L10709

Screen JA, Simmonds I, Deser C, Tomas R (2013) The atmospheric response to three decades of observed Arctic sea ice loss. J Clim 26:1230-1248

Screen JA et al (2018) Consistency and discrepancy in the atmospheric response to Arctic sea-ice loss across climate models. Nat Geosci 11:155-163

Serreze MC, Barrett AP, Stroeve JC, Kindig DN, Holland MM (2009) The emergence of surface-based Arctic amplification. Cryosphere 3:11-19

Skific N, Francis JA (2013) Drivers of projected change in Arctic moist static energy transport. J Geophys Res Atmos 118:2748-2761

Smith DM, Dunstone NJ, Scaife AA, Fiedler EK, Dan C, Hardiman SC (2017) Atmospheric response to Arctic and Antarctic sea ice: the importance of ocean-atmosphere coupling and the background state. J Clim 30:4547-4565

Sorokina SA, Li C, Wettstein JJ, Kvamst $\varnothing$ NG (2016) Observed atmospheric coupling between Barents sea ice and the warm-Arctic cold-Siberian anomaly pattern. J Clim 29:495-511

Spielhagen RF et al (2011) Enhanced modern heat transfer to the Arctic by warm Atlantic water. Science 331:450-453

Stroeve JC, Serreze MC, Holland MM, Kay JE, Malanik J, Barrett AP (2012) The Arctic's rapidly shrinking sea ice cover: a research synthesis. Clim Change 110:1005-1027
Sun L, Deser C, Tomas RA (2015) Mechanisms of stratospheric and tropospheric circulation response to projected Arctic sea ice loss. J Clim 28:7824-7845

Sun L, Perlwitz J, Hoerling M (2016) What caused the recent "warm Arctic, cold continents" trend pattern in winter temperatures? Geophys Res Lett 43:5345-5352

Sung M-K, Kim S-H, Kim B-M, Choi Y-S (2018) Interdecadal variability of the warm Arctic and cold Eurasia pattern and its North Atlantic origin. J Clim 31:5793-5810

Svendsen L, Keenlyside N, Bethke I, Gao Y, Omrani N-E (2018) Pacific contribution to the early twentieth-century warming in the Arctic. Nat Clim Change 8:793-797

Takaya K, Nakamura H (2005) Mechanisms of intraseasonal amplification of the cold Siberian high. J Atmos Sci 62:4423-4440

Tao S, Chen L (1987) A review of recent research of the east Asian summer monsoon in China. In: Change CP, Krishnamurti TN (eds) Monsoon meteorology. Oxford University Press, pp 60-92

Vavrus SJ (2018) The influence of Arctic amplification on mid-latitude weather and climate. Curr Clim Change Rep 4:238-249

Wang L, Chen W (2014) The East Asian winter monsoon: re-amplification in the mid-2000s. Sci Bull 59:430-436

Woods C, Caballero R (2016) The role of moist intrusions in winter Arctic warming and sea ice decline. J Clim 29:4473-4485

Xu X, He S, Li F, Wang H (2018) Impact of northern Eurasian snow cover in autumn on the warm Arctic-cold Eurasia pattern during the following January and its linkage to stationary planetary waves. Clim Dyn 50:1993-2006

Xu X, He S, Gao Y, Furevik T, Wang H, Li F, Ogawa F (2019) Strengthened linkage between midlatitudes and Arctic in boreal winter. Clim Dyn 53:3971-3983

Xu X, He S, Furevik T, Gao Y, Wang H, Li F, Ogawa F (2020) Oceanic forcing of the global warming slowdown in multi-model simulations. Int J Climatol 40:5829-5842

Zhang X, Sorteberg A, Zhang J, Gerdes R, Comiso JC (2008) Recent radical shifts of atmospheric circulations and rapid changes in Arctic climate system. Geophys Res Lett 35:L22701

Zhong L, Hua L, Luo D (2018) Local and external moisture sources for the Arctic warming over the Barents-Kara Seas. J Clim 31:1963-1982

Zhou W (2017) Impact of Arctic amplification on East Asian winter climate. Atmos Ocean Sci Lett 10:385-388

Publisher's Note Springer Nature remains neutral with regard to jurisdictional claims in published maps and institutional affiliations. 